\title{
Wikificando a História da Física \\ A Web 2.0 na construção colaborativa de conhecimento no Ensino
}

\author{
Renato P. dos Santos \\ ULBRA/PPGECIM \\ e-mail: renato@renatops.info
}

SL: Otaner Merlin

\section{Resumo}

Este trabalho é um relato preliminar da nossa experiência de utilização de ferramentas da Web 2.0 na construção colaborativa de conhecimento durante a disciplina 'História e Epistemologia da Física', do curso de Licenciatura Plena em Física da Universidade Luterana do Brasil. Incluímos dentre as atividades da disciplina, acrescentar (upload) material novo à Wikipédia e ao wikilivro contendo as notas de aula desta disciplina, em vez de o aluno meramente copiar e colar (download) o material existente já pronto na Internet durante a produção de materiais escritos. Embora a experiência tenha sido entusiasticamente aprovada, o número de contribuições ainda é pequeno. No entanto, o resultado maior desta proposta é a conscientização pós-positivista da Ciência como um processo humano, social e cooperativo de construção de conhecimento, de acordo com os objetivos da disciplina.

Palavras-chaves: texto coletivo, cooperação, colaboração, Wikipédia, Wikilivros

\section{Wikifying the History of Physics \\ Web 2.0 in collaborative knowledge building in teaching}

This paper is a preliminary report of our experience with the use of Web 2.0 tools in collaborative knowledge building during the 'History and Epistemology of Physics' class from the Brazilian Lutheran University's Physics Course. Among the class activities we included adding (upload) new material to Wikipedia and to the wikibook containing the class notes, instead of the student merely copying and pasting (download) the already existing material on the Internet when producing written materials. Although the experience has been enthusiastically adopted, the number of contributions is still small. However, the result of this proposal is the largest postpositivist awareness of Science as a human, social and cooperative construction of knowledge, according to the class objectives.

Key words: collective text, cooperation, collaboration, Wikipedia, Wikibooks

\section{Introdução}

Este trabalho é um relato preliminar da nossa experiência de utilização de ferramentas da Web 2.0, especialmente a Wikipédia e o Wikilivros na construção colaborativa de conhecimento durante a realização no semestre 2008/1 da disciplina 'História e Epistemologia da Física', do curso de Licenciatura Plena em Física da Universidade Luterana do Brasil, no campus Canoas, RS. Pretende promover reflexões sobre a utilização de ferramentas da Web 2.0 na construção colaborativa e, por esse motivo, não apresenta análises mais aprofundadas dos dados obtidos.

A Ementa dessa disciplina inclui não só os tópicos usuais da História da Física, desde a Grécia até nossos dias, mas também questões epistemológicas, tais como 'O que é Ciência?', Indutivismo, Racionalismo, Positivismo e Pós-Positivismo. Com isso, pretende situar o aluno dentro da evolução do pensamento físico, discutindo cada 
etapa da história da Física em sua complexidade histórico-epistemológica e não como mero amontoado de fatos e datas. Pretende oportunizar aos estudantes que compreendam a Ciência como uma construção humana, demonstrando a indissociabilidade do lado humano do cientista, bem como a inserção de seu pensamento no seu contexto histórico, político, econômico, ideológico, artístico e social. Por outro lado, pretende demonstrar a importância da vinculação dos aspectos históricos ao trabalho de sala de aula com alunos de ensino fundamental e médio para que os mesmo possam compreender de forma mais clara os conceitos físicos e associar esses conhecimentos com as metodologias e estratégias do ensino da Física. Para tanto, além das aulas dialogadas, apoiadas sempre em recursos áudio-visuais, ocorrem palestras públicas semanais proferidas pelos próprios alunos, inseridas no Projeto Vida e Obra do Curso de Licenciatura em Física, sobre a vida e a obra de eminentes cientistas.

Apesar do entusiasmo e do bom resultado obtido nas palestras acima mencionadas no semestre passado, observamos, durante a produção do correspondente material escrito, tendência à conhecida prática do copiar e colar da Internet. De fato, parece haver certo consenso entre os alunos de que "pode tudo na internet" (LEMOS, 2005b). Nossos alunos vivem na atual cibercultura, sob o princípio da "re-mixagem" e, para VALENTE \& MATTAR (2007, p. 87), "provavelmente, não compreendemos mais o público para o qual damos aulas hoje."

Na Web 2.0, tudo é matéria-prima para ser usada e remixada, tal como fazem os DJ's na música hiphop com seus Sound Systems. Segundo Lemos (2005b), com o surgimento do pós-modernismo, em meados do século $X X$, pela primeira vez, na história da humanidade, qualquer indivíduo pode receber informação alterá-la, adicionar e colaborar com pedaços de informação criados por outros e reemitir em tempo real, sob diversos formatos e modulações, para qualquer lugar do planeta. Essa é a cultura em que vivemos. Não um futuro que vai chegar, mas a cultura do nosso presente, marcada pelas tecnologias digitais do home banking, dos cartões inteligentes, celulares, palms, pages, voto eletrônico, imposto de renda via rede, etc. (LEMOS, 2005).

Como lembra Garcia (2007), a excitação e do frenesi dos jovens para participar de tudo isso contrasta fantasticamente com a apatia e desinteresse que os professores se queixam dos mesmos na sala de aula. A maioria dos professores ainda não se deu conta que não existe mais aquele cândido aluno, sentado de maneira comportada em sua carteira, a ouvir as preleções de seu mestre. De qualquer forma, não temos força para mudar essa cultura e voltar aos "bons velhos tempos"; caberá ao professor adaptar-se e transformar o obstáculo em oportunidade de crescimento.

Para Garcia (2008), a educação tradicional é tipicamente um processo download: o estudante recebe textos do professor e os lê a fim de memorizá-los, não Ihes sendo permitido alterar ou melhorar esses textos. Em 1994, entretanto, Ward Cunningham, programador americano de computadores, criou um sistema que permitia que utilizadores alterassem o conteúdo exibido. O mais conhecido dos muitos projetos baseados nesse conceito bastante upload é a Wikipedia.

A Wikipédia ${ }^{1}$ é uma enciclopédia eletrônica cujo conteúdo é livre e regido pelos termos da licença conhecida como GFDL (Gnu Free Documentation License), que permite que todo o conteúdo possa ser livremente copiado, alterado e redistribuído por terceiros, desde que sejam dados os devidos créditos (SOBRE a Wikipédia). Com seus mais de 5 milhões de artigos em dezenas de línguas, quase 400.000 em português, (SOBRE a Wikipédia), tem como vantagem em relação à Britannica e outras a possibilidade de ser atualizada imediatamente e escrita por qualquer pessoa em qualquer lugar do mundo. O sistema usa páginas que podem editadas, as "wikis", 
permitindo que qualquer usuário possa editar, apagar ou criar novos verbetes (LEMOS, 2005b), um evidente exemplo do princípio de re-mixagem.

O projeto Wikilivros ${ }^{2}$ é uma coleção de livros abertos que são escritos de forma colaborativa no site wikibooks.com. O projeto original em inglês teve início no dia 10 de julho de 2003. A versão em português migrou para uma wiki própria no dia 22 de julho de 2004 e possui 5856 artigos trabalhados.

A Wikipédia é um exemplo bem sucedido de uma atividade coletiva humana de construção do conhecimento, "um produto da inteligência coletiva" (CARVALHO, ROCHA, FREITAS, 2007). No entanto, a sua estrutura aberta permite que qualquer indivíduo altere seu conteúdo $e$, assim, não se pode garantir que cada um dos verbetes tenha sido revisado por especialistas nas áreas de conhecimento correspondentes, de modo a poder garantir informações completas, precisas e confiáveis. Qualquer verbete pode ter sido vandalizado ou até alterado por alguém cuja opinião não corresponde ao "estado do conhecimento" naquela área específica de conhecimento (AVISO Geral).

Esse parece ser o maior argumento para que a Wikipédia tenha tão pouca credibilidade dos círculos acadêmicos. Mas uma busca na base de currículos Lattes revela que já há importantes acadêmicos criando e colaborando em artigos. No entanto, Larry Sanger, Ph.D. em Filosofia e editor do fracassado projeto Nupedia, precursor da Wikipédia é de opinião que a comunidade da Wikipédia tem pouco respeito para com especialistas, citado em COELHO da COSTA, 2007). Por outro lado, esse autor concede que, embora a taxa de erro na Wikipédia, na Britannica ou qualquer outra enciclopédia, não seja boa o suficiente para serem citadas (vide, p. ex, VIEIRA, 2008), é mais confiável ler a Wikipédia do que páginas ao acaso na Internet (SANGER, 2004).

Carvalho (2007) conclui que "a atitude crítica diante do que é publicado e a possibilidade de participação ativa na construção do conhecimento são atividades educativas que podem ser estimuladas pelo seu uso." Anastácio (apud CARVALHO, 2007), considera que a Wikipédia é um excelente meio para esse fim pois, fazendo-os participar na sua construção, nossos jovens serão melhores cidadãos do que aqueles que leiam apenas textos 'oficiais' como se fossem verdades absolutas (grifo nosso).

Na próxima seção, descrevemos as estratégias usadas para levar os alunos da disciplina a participar nessa construção coletiva de conhecimento e, indiretamente, desenvolver atitude crítica diante do que está publicado.

\section{Metodologia}

$\mathrm{Na}$ realização anterior desta disciplina, fizemos uso dos recursos web disponibilizados pela Ulbra na forma de um "site da disciplina", dentro do sistema de auto-atendimento da Ulbra. Nesse site, carregamos todos os materiais a que os alunos teriam acesso, tais como o programa da disciplina, lâminas das aulas produzidas em Powerpoint, indicações de sites e artigos para consulta, bibliografia recomendada, etc.

No entanto, apesar de todo o sucesso propalado pelo Ensino a Distância, Garcia (2008) chama a atenção para que a maioria dos métodos em uso, tais como Ambientes Virtuais de aprendizado, com seus objetos de aprendizado disponibilizados na web, ainda seguem o paradigma do download.

Tendo em conta essa problemática, decidimos tentar mudar a equação

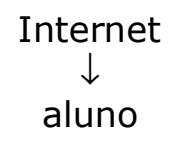


para

\author{
Internet \\ $\uparrow \downarrow$ \\ aluno
}

Ou seja, em vez de o aluno copiar (download) o material existente já pronto na Internet, ele é desafiado a acrescentar (upload) material novo ao que já lá existe. Com isso, o aluno, além de leitor, passa a ser, também, colaborador, editor, autor e produtor de material didático para uma audiência que ultrapassa os limites da sala de aula ou mesmo do ambiente de aprendizagem (VALENTE \& MATTAR, 2007, p. 85).

Para tanto, decidimos este ano intensificar o desafio, levando os alunos a participarem ativamente na construção do conhecimento em nível pessoal e comunitário, imerso que estão num mundo globalizado, mediado pela Internet 2.0, incluindo, dentre as atividades da disciplina, a produção de materiais em regime cooperativo e de conteúdo aberto:

- contribuição substancial ao verbete da Wikipédia correspondente ao cientista objeto da palestra acima mencionada.

- contribuição substancial ao wikilivro contendo as notas de aula desta disciplina ${ }^{3}$.

Para poder participar dessas atividades, o aluno teve de, ao início do semestre:

- inscrever-se no HisFis - 'Grupo de discussão da Disciplina de História e Epistemologia da Física'4

- consultar o arquivo Cronograma de Palestras, disponibilizado no "site da disciplina", escolher uma data para a palestra, dentre as indicadas e disponíveis e enviar mensagem para o grupo HisFis, indicando também o cientista desejado;

- criar conta de usuário na Wikipédia e no Wikilivros, divulgando-o na lista de discussão, para conhecimento de todos e monitoramento das contribuições, permitindo suas avaliações.

De posse dos nomes de usuário, é possível, então, monitorar as contribuições de cada aluno, tanto na Wikipédia como no Wikilivros, como se vê na Figura 1 (a figura foi editada por forma a garantir a confidencialidade do aluno). 


\section{r}

Para Dga (discussẫo | Registo de bloqueio | Registos)

-Busca de contribuiçỗes

Mostrar apenas contribuiçốes de novas contas

c. IP ou usuário: Dga Domínio: todos

A partir do ano: $\quad$ A partir do mês: todos $\quad$ Busca

(Mais recentes | Mais antigas) Ver (50 posteriores) (50 anteriores) (20 | 50 | $100|250| 500$ ).

- $10 \mathrm{h02min}$ de 28 de Maio de 2008 (hist) (dif) Big Splash ( $\rightarrow$ Lua)

- 08h45min de 28 de Maio de 2008 (hist) (dif) Stephen Hawking ( $\rightarrow$ Biografia) (última alteraçăo)

- 08h48min de 14 de Maio de 2008 (hist) (dif) Usuário:Dga (última alteraçăo)

- 08h46min de 14 de Maio de 2008 (hist) (dif) Stephen Hawking ( $\rightarrow$ Obras publicadas)

- 08h46min de 14 de Maio de 2008 (hist) (dif) Stephen Hawking ( $\rightarrow$ Obra)

Figura 1 - Levantamento das contribuições do aluno Dga à Wikipédia

Para efeitos de avaliação, serão levados em conta os critérios de aderência aos padrões discursivos da Wikipédia e do Wikilivros, em cada caso, especialmente os referentes a correção, objetividade, imparcialidade, documentação das fontes, etc., precisão, concisão e profundidade. Para o verbete da Wikipédia, serão levados em conta ainda: interesse; originalidade; explicitação da relação de vida e obra do cientista retratado com seu contexto histórico, político, econômico, ideológico e social; e recursos utilizados.

No entanto, toda esta proposta só se torna viável pela simplicidade do processo de wikificação ${ }^{5}$ do material, isto é, formatar o texto, inserir imagens ou criar links, sem conhecimentos especiais, permitindo que os estudantes despendam mais tempo desenvolvendo conteúdo e menos tempo trabalhando a forma (MADER, 2006).

Para avaliar a apreciação dos alunos com a proposta, dificuldades com os meios e outros pontos de interesse, foi enviada via o grupo HisFis uma mensagem contendo um questionário com quatorze perguntas abertas envolvendo vários aspectos da disciplina. Apenas sete dos dez inscritos no grupo enviaram suas respostas e estas serão analisadas na seção seguinte.

\section{Resultados}

No geral, a disciplina está tendo um desenvolvimento muito a contento dos alunos. Dtr afirma que "essas aulas são ótimas" e que "quem me conhece bem estranha quando digo que uma das melhores aulas é a de História" mesmo não tendo 'continha'. Efs declara que "estou aprendendo como nunca". Dga diz que gosta muito da relação entre os alunos e o professor e "me sinto completamente à vontade para participar, brincar e questionar." Dtr diz: "estou achando a disciplina muito boa, na verdade, muito, muito boa!" A proposta também é aprovada por Dtr quando diz que a disciplina "é exatamente o que como professores precisaremos, e não apenas nessa esfera mas também para entendermos o porquê de certas coisas." A estratégia das palestras foi visto por Dga como "o acontecimento universitário até agora", por Ero, "um de meus melhores trabalhos" e por Efs, como "uma oportunidade única". Para Dtr, "foi também uma coisa diferente, apresentar p/ alguns colegas, alguns professores, 
e umas 2 ou 3 pessoas que eu não conhecia", apesar de ter ficado "muito nervosa na palestra" e "uns três dias" antes, também. Acs ficou "impressionado com o apoio e suporte por parte dos professores em geral, nós alunos nos sentimos muito à vontade e seguros, sem levar em conta que as palestras nos tornam dinâmicos, desinibidos e articulados."

A utilização de recursos mediáticos parece ter ido de encontro à cultura de nossos jovens. Acs ainda pede mais: "o material utilizado é excelente e as ilustrações (desenhos, esquemas) também", mas "acredito que poderia utilizar mais desenhos ou simulações que possam contextualizar a época que esta sendo estudado."

O objetivo de demonstrar a importância da vinculação dos aspectos históricos ao trabalho de sala de aula parece também estar sendo atingido para Lsc, que diz que a disciplina "tem a acrescentar tanto em algumas disciplinas da faculdade como nas aulas em escolas."

Curiosamente, feita a divulgação da criação do grupo de discussão na lista de discussão do curso de Física (pré-existente, na qual quase todos os alunos do curso já estão inscritos), vários alunos que já cursaram essa disciplina no ano anterior inscreveram-se também (na verdade, antes que qualquer dos alunos regulares da disciplina), como "ouvintes" para acompanhar o desenvolvimento da nova proposta. Vale notar que, tanto o coordenador do curso de Física como o laboratorista, também se inscreveram. O grupo HisFis, embora tenha sido útil para gerir a troca de mensagens entre os alunos e com o professor, não chegou a ter uma dinâmica de grupo de discussão, "anda meio parado" (Dtr), "as únicas interações são feitas através do professor" (Dga). Apesar disso, foi visto como "genial" (Acs), "válido" (Gsc), "uma ótima ferramenta" (Dtr), não tendo os alunos vindo a "discutir uns com os outros e comentar a relevância de cada assunto postado na plataforma" (Acs) por falta de tempo (Gsc e Acs) ou outras dificuldades técnicas (Ero e Lsc). Por outro lado, o contato por e-mail com o professor, na visão dos alunos, é "muito ágil e eficiente" (Efs), "útil, bem atualizado e eficaz" (Dga), o professor é "sempre presente e preciso nas respostas (Acs).

A experiência de escrever na Wikipédia foi aprovada:

Acs: Interessante, é uma forma de nos incentivar a compartilhar informações e aprender a fazer nosso marketing pessoal no que diz respeito a publicação e disseminação do saber.

Efs: Gostaria de ter mais tempo para escrever na Wikipédia. Gosto de participar da construção de conhecimentos.

Lsc: É bom acrescentarmos algo para facilitar os estudos de outros indivíduos e os meus, porque assim tenho que ter certeza, pesquisando muito, do que estou escrevendo para não acrescentar algo errado.

A Figura 2 apresenta um exemplo de colaboração do aluno Ggo ao verbete 'Dmitri Mendeleiev' da Wikipédia, tema de sua palestra. 
versão da tabela periódica de Mendeleev, da primeira ediçâo

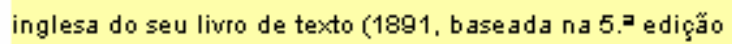

russa)]]Nessa época todos os seus irmãos, exceto uma irmã, já

viviam independentemente. Sua mãe entâo mudou-se com

ambos para [[Moscou]] a fim de que ele ingressasse na

- universidade o que não conseguiu. Talvez devido a clima

político vivido pela Rússia naquele momento a universidade só

admitia moscovitas. Interessou-se pela química graças ao

prestigiado professor Alexander Vokresenki, que passou seus

últimos anos de vida em uma enfermaria devido a um falso

diagnóstico de [[tuberculose]]. Ainda assim graduou-se em 1855

como primeiro de sua classe.

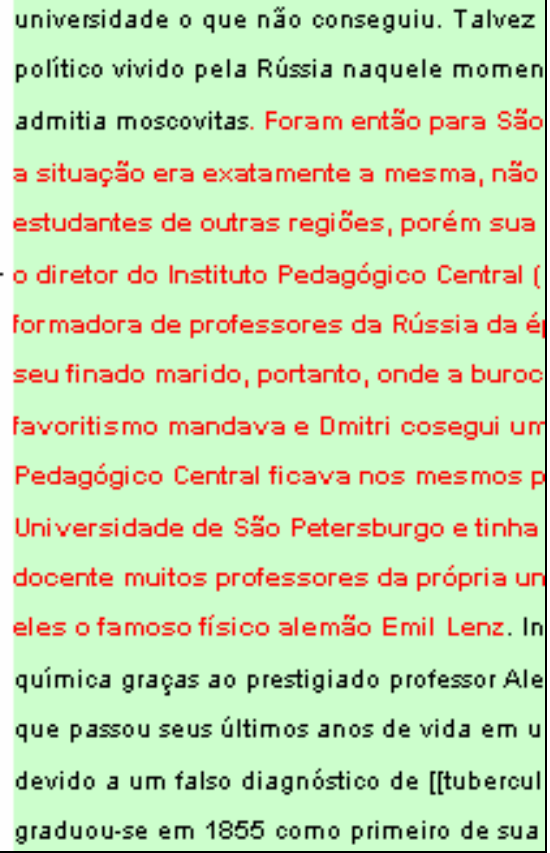

universidade o que năo conseguiu. Talvez

político vivido pela Rússia naquele momen admitia moscovitas. Foram entăo para São a situação era exatamente a mesma, não estudantes de outras regiões, porém sua + o diretor do Instituto Pedagógico Central formadora de professores da Rússia da é seu finado marido, portanto, onde a buroc favoritismo mandava e Dmitri cosegui un Pedagógico Central ficava nos mesmos $\mathrm{P}$ Universidade de Săo Petersburgo e tinha docente muitos professores da própria ur eles o famoso físico alemão Emil Lenz. In química graças ao prestigiado professor Ale que passou seus últimos anos de vida em u graduou-se em 1855 como primeiro de sua

Figura 2 - Contribuição do aluno Ggo ao verbete da Wikipédia

No entanto, apesar dos comentários favoráveis, até a data da preparação deste trabalho, três dos treze alunos da disciplina ainda não se registraram na Wikipédia. Dos dez inscritos, apenas quatro, Ggo, Dga, Acs e Dtr até esta data fizeram alguma modificação em qualquer página da Wikipédia, sendo que Dtr apenas incluiu algumas informações em sua página pessoal de usuário. As razões alegadas foram falta de tempo, "vou fazer no próximo feriado, pois cheguei de viagem a apenas alguns minutos e não terei tempo hoje" (Gsc) e dificuldades técnicas, "A Wikipédia não permite colar o arquivo que tenho salvo em formato do Word no meu computador lá de casa. Então tenho que achar uma maneira de escrevê-lo on line" (Erro). Apesar disso, Dga aprovou: "Escrever na Wikipédia foi complicado no começo, mas achei bom, tanto que pretendo continuar!" dificuldades:

Mas, apesar da simplicidade da sintaxe da wiki, essa experiência não foi sem

Dga: As dificuldades na wikipédia foi a de edição e postagem de material apropriado, tenho dificuldade na edição como, por exemplo, para adicionar referências.

Acs: Não tenho como negar que no inicio tive dificuldade sim, creio que poderíamos ter um esclarecimento inicial, assim não perderia tempo e produziria mais. O lado positivo foi o de encontrar sozinho, isto gera motivação e independência.

Efs: Algumas, mas facilmente sanadas em aula.

Lsc: No começo para acessá-la, mas você me explicou e ficou tudo certo.

Apesar de haver na Wikipédia um tutorial orientando os primeiros passos na edição, aparentemente os alunos não o procuraram, não o encontraram ou não o leram. Propositalmente não foi feita uma indicação para este tutorial, com o objetivo de avaliar a aplicação à Wikipédia da pergunta de VALENTE \& MATTAR (2007, p. 87) 
"quem precisa se preocupar em ensinar um jovem a usar o MSN? Quem já mandou seu filho fazer um curso para utilizar o Orkut?" Aparentemente, pelo menos no que concerne a esta amostra, deveríamos nos ter preocupado. Com relação ao acesso ao material da disciplina disponibilizado on-line, os alunos relataram ter tido "nenhuma dificuldade" (Acs, Efs, Lsc) ou "poucas" (Gsc), devidas a "indisponibilidade em termos de internet" (Ero) ou por ter acesso discado (Dtr). Mas rapidamente estava "tudo correndo de acordo" (Dga). Isto parece demonstrar que os alunos não eram desprovidos do necessário domínio de Internet para as atividades propostas. De um ponto de vista da teoria de Vygotsky (1998), no entanto, se movimentar-se no espaço do auto-atendimento da Ulbra poderia ser enquadrado em seu Nível de Desenvolvimento Real, o trabalho na Wikipédia e no wikilivro já estaria no Nível de desenvolvimento Potencial, sendo necessária a intervenção de colegas mais experientes ou do próprio professor da disciplina para que os alunos pode desenvolvelo a contento. De fato, Dga afirma que "temos que enfrentar exigências e aprender a lidarmos com algumas coisas que por ventura não gostamos" e também que "nenhum colega nega ajuda ao outro".

Nas próximas edições desta disciplina, pretendemos disponibilizar um pequeno documento com screenshots indicando onde se localizam os botões e abas necessários para a edição. positiva:

Da mesma forma, a experiência de escrever no Wikilivro foi considerada

Dtr: Achei interessante esse esquema do Wikibook, é fácil de mexer (não um mostro de mil e uma cabeças como alguns estavam falando), porém a "inércia" tá falando mais alto por enquanto né 'sor'?!!! rsrs... mas vou tentar me mexer pra esses dois!! vou tentar!!! dê mais puxões de orelha caso esqueça, rsrs.

Gsc: Muuuuuuuito interessante, sempre que puder vou escrever.

Ero: Que dificuldade. Mas quero ainda escrever mais coisas que tenho nas gravações que faço.

Dos dez inscritos, apenas um, Erro, até esta data não fez qualquer contribuição ao nosso Wikilivro. Observando muito pouca participação dos alunos, numa tentativa de vencer a "inércia" apontada por Dtr, os autores decidiram, sentindo-se permitidos pelo clima de cumplicidade construída com os alunos ao longo da convivência, exercer certa pressão, divulgando um falso aviso, através de uma mensagem por e-mail, enviada no dia primeiro de abril, o conhecido Dia da Mentira, de que as páginas no wikilivro referentes às aulas já dadas teriam seus acessos bloqueados, impedindo, assim, o cumprimento das tarefas em atraso. Sete alunos contribuíram imediatamente nos dias seguintes. De fato, Gsc mencionou "acho que não vou ter [dificuldades], quando escrever [na Wikipédia], pois já estou familiarizado com o Wikibook".

E quanto a dificuldades:

Dga: As dificuldades no Wikibook foram maiores, acho que por estar lidando com uma ferramenta desconhecida, não tinha idéia de como aquilo funcionava, na verdade é praticamente igual ao wikipedia.

Gsc: Apenas de como iniciar, mas depois que descobri como fazer, é como estudar física... uma maravilha.

Analisando as colaborações e conversando com os alunos em sala de aula, chegamos à conclusão de que a proposta de produzir o wikilivro das notas de aula da 
disciplina, dada a extensão dos conteúdos tratados, não está sendo vista como viável pelos alunos. Como comenta Dga, "sobre o Wikibook, acho que já foi comentado em sala de aula, foi um pouco audacioso o projeto". Lsc acha que "para dar tempo do pessoal fazer a palestra e escrever no Wikipédia e no Wikibook, poderia ter pedido [apenas] um dos dois" (Wikipédia ou wikilivro). Acreditamos, no entanto, que são dois trabalhos diferentes e que devem ser mantidos. No entanto, devemos repensar a atividade no Wikilivros, para que não aconteça da extensão da proposta impressionar negativamente os alunos.

Embora a disciplina ainda esteja em andamento quando da preparação deste trabalho, podemos imaginar de antemão o impacto cognitivo positivo que essa mudança de direção no fluxo do conhecimento pode ter sobre nossos alunos se aceitarmos o argumento de Garcia (2008):

"Quando você dá alguma coisa a alguém, você dá parte de si mesmo. Uma parte da sua história. Uma parte da sua vida. É difícil esquecer isso. Por outro lado, quando você recebe alguma coisa de alguém, o que você recebe não é realmente seu. É parte da vida de outra pessoa, de sua história. Só lembramos das coisas mais expressivas que recebemos. O resto é geralmente fácil de esquecer."

Nas palavras de Anastácio (apud CARVALHO, 2007), é difícil, para a maioria das pessoas, compreender a comoção quase mística que toma o wikipedista quando vê o "seu" artigo despretensioso na Wikipédia traduzido para outras línguas. Alguém completou suas palavras, e, em vez de irritar-se por alguém ter "mexido" no seu texto, sente-se grato por isso.

Sumarizando, acreditamos que a experiência está sendo bem sucedida, conseguindo uma alteração na visão epistemológica dos alunos, de "Ciência pronta" para "Ciência como construção". Lsc acha "esta disciplina importante para sabermos como a ciência física se originou, saber de onde vêm as coisas, fica mais fácil entender certos 'mitos' entre outras coisas." Dga considera que "a disciplina é extremamente importante, por dar a noção de onde surgiu aquilo tudo que estudamos, pra entendermos por que a ciência hoje funciona assim, por que é como é. Acho que seu objetivo de colocar dúvida na ciência que temos hoje já foi atingido." De fato, Dga observou que "sempre que um assunto deste gênero [assuntos polêmicos] é abordado a turma se agita" Com isso, o resultado maior desta proposta é a conscientização póspositivista da Ciência como um processo humano, social e cooperativo de construção de conhecimento, de acordo com os objetivos da disciplina.

\section{Conclusões}

A Wikipédia, com o interesse de manter qualidade (o que acho essencial), inevitavelmente, como qualquer pessoa ou instituição, faz julgamentos sobre as coisas (no caso, a tal "qualidade"), querendo, por exemplo, evitar inconsistências - mas o inconsistente sempre varia conforme as ideologias: seria preciso ser perfeitamente correto na opinião de todos, e isto está para além da condição humana, porque o homem sempre faz uma escolha, transmitindo sua visão das coisas ${ }^{6}$.

Segundo Valente \& Mattar (2007, p. 147), em todas as comparações já realizadas, a Wikieducação sempre superaria tanto educação presencial quanto a educação a distância.

A disciplina está tendo um desenvolvimento bastante a contento. O objetivo da disciplina de conscientização pós-positivista da Ciência como um processo humano, 
social e cooperativo de construção de conhecimento, está sendo atingido de maneira, concreta, pela experiência pessoal e imediata dos alunos.

Por outro lado, em se tratando de alunos que em poucos meses estarão se lançando no mercado de trabalho, é importante lembrar Mader (2006), segundo o qual, à medida que mais e mais organizações adotam o modelo wiki para colaboração e circulação de informação, melhor estarão nossos estudantes preparados para usá-lo em suas carreiras. Para Acs, "já é uma forma de enriquecer e ampliar nosso currículo." Essa experiência pode ter vários impactos, dentre eles, "aprender a fazer nosso marketing pessoal" (Acs).

O autor agradece sinceramente a colaboração dos wikipedistas contatados, o firme apoio recebido do Prof. Moacyr Marranghelo, Coordenador do Curso de Física, e o entusiasmo e amizade dos alunos desta disciplina, tanto desta edição como da anterior, em 2007/1.

As informações e opiniões emitidas aqui são de inteira responsabilidade de seus autores, não representando, necessariamente, posição oficial da Universidade Luterana do Brasil ou de sua mantenedora.

\section{Notas}

${ }^{1}$ A versão lusófona da Wikipedia adotou por convenção a forma "Wikipédia", acentuada (FAQ Geral, disponível em: <http://pt.wikipedia.org/wiki/Wikipedia:FAQ_Geral>).

${ }^{2}$ A versão lusófona do Wikibooks aparentemente adotou a forma "Wikilivros", embora os autores deste trabalho não tenham conseguido encontrar uma referência a essa convenção.

${ }^{3}$ Disponível em: <http://pt.wikibooks.org/wiki/História_e_Epistemologia_da_Física>

${ }^{4}$ Disponível em: <http://www.grupos.com.br/group/hisfis_ulbra/>

${ }^{5}$ Wikificação é o ato de formatar uma página para o padrão wiki, utilizado nos projetos baseados na plataforma wiki, tais como a Wikipédia, o Wikilivros, etc.

${ }^{6}$ CAVALCANTI, Camillo. Re: contribuições à Wikipédia. [mensagem pessoal]. Mensagem recebida por <renato@reniza.com> em 17 de maio de 2008 17:43.

\section{Referências}

AVISO Geral. In: Wikipédia: a enciclopédia livre. Disponível em: <http://pt.wikipedia.org/wiki/Wikipedia:Aviso_Geral>. Acesso em: 12 maio 2008.

SOBRE a Wikipédia. In: Wikipédia: a enciclopédia livre. Disponível em: <http://pt.wikipedia.org/wiki/Wikipedia:Sobre_a_Wikipédia>. Acesso em: 11 maio 2008.

WIKIFICAÇÃO. In: Wikipédia: a enciclopédia livre. Disponível em: <http://pt.wikipedia.org/wiki/ Wikipedia:Wikificação>. Acesso em: 11 maio 2008.

CARVALHO, Adriane Maria Arantes de; ROCHA, Eliane Cristina de Freitas; FREITAS, Wladimir Mendes de. Cultura Hacker e a Colaboração na Wikipédia. In: Anais do XXX Congresso Brasileiro de Ciências da Comunicação Intercom, 2007, Santos - SP. São Paulo : Intercom - Sociedade Brasileira de Estudos Interdisciplinares da Comunicação, 2007. Disponível em: <http://www.intercom.org.br/papers/nacionais/2007/resumos/R1103-3.pdf>. Acesso em: 15 maio 2008.

COELHO da COSTA, Antonio Luiz Monteiro. Referência fast-food. Carta Capital, fev. $2007 . \quad$ Disponível em: <http://cartacapital.com.br/edicoes/2007/02/431/referencia-fast-food>. Acesso em: 12 maio 2008. 
GARCIA, Maurício. Efeito Katilce : Como o Youtube, o Second Life e outros recursos da Web 2.0 vão mudar o setor da educação. 2007. Disponível em <http://www.mgar.com.br/mgPdf/2007_07_EfeitoKatilce.pdf>. Acesso em: 21 maio 2008

GARCIA, Maurício. Download or Upload? The use of technology for higher education learning and management. In: Anais do XXV Jubilee World Buiatrics Congress, Budapest, July 6-11, 2008. Disponível em <http://www.mgar.com.br/mgPdf/2008_01_DownlodUpload.pdf>. Acesso em: 21 maio 2008

LEMOS, André Luiz Martins. O Papa é Ciber. Revista Novae, 05 abr. 2005. Disponível em: <http://www.novae.inf.br/pensadores/papa_ciber.htm>. Acesso em: 16 maio 2008.

LEMOS, André Luiz Martins. Ciber-Cultura-Remix. In seminário "Sentidos e Processos", Centro Itaú Cultural, São Paulo, 2005. ago. 2005. Disponível em: <http://www.facom.ufba.br/ciberpesquisa/andrelemos/remix.pdf>. Acesso em: 15 maio 2008.

MADER, Stewart. Ways to use Wiki in Education. In: Stewart Mader, Using Wiki in Education. 24 out. 2006, 12:00 UTC. Disponível em <http://www.wikiineducation.com/display/ikiw/Ways+to+use+wiki+in+educati on>. Acessado em 23 maio 2008.

SANGER, Larry. Why Wikipedia Must Jettison Its Anti-Elitism. In kuro5hin.org site. 2004.

Disponível

em: <http://www.kuro5hin.org/story/2004/12/30/142458/25>. Acesso em: 12 maio 2008.

VALENTE, Carlos; MATTAR, João. Second Life e Web 2.0 na Educação : o potencial revolucionário das novas tecnologias. São Paulo : Novatec, 2007.

VIEIRA, Marli Fátima Vick. A Wikipédia é Confiável: Novas formas de autoria e trabalho colaborativo para produção do conhecimento numa enciclopédia virtual online. Dissertação (Mestrado em Educação) - Universidade do Vale do Itajaí, 2008.

VYGOTSKY, Lev Semionovitch. A Formação Social da Mente: o Desenvolvimento dos Processos Psicológicos Superiores. Editora Martins Fontes, São Paulo, 1998. 